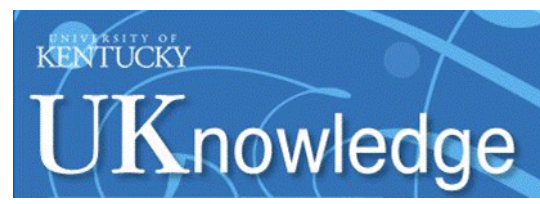

University of Kentucky

UKnowledge

7-7-2015

\title{
Arm Dominance Does Not Influence Measures of Scapular Muscle Strength and Endurance in Healthy Individuals
}

Joseph M. Day

University of South Alabama

Heather M. Bush

University of Kentucky, heather.bush@uky.edu

Arthur J. Nitz

University of Kentucky, arthur.nitz@uky.edu

Tim L. Uhl

University of Kentucky, tluhl2@uky.edu

Follow this and additional works at: https://uknowledge.uky.edu/rehabsci_facpub

Part of the Rehabilitation and Therapy Commons

Right click to open a feedback form in a new tab to let us know how this document benefits you.

\section{Repository Citation}

Day, Joseph M.; Bush, Heather M.; Nitz, Arthur J.; and Uhl, Tim L., "Arm Dominance Does Not Influence Measures of Scapular Muscle Strength and Endurance in Healthy Individuals" (2015). Physical Therapy Faculty Publications. 51.

https://uknowledge.uky.edu/rehabsci_facpub/51

This Article is brought to you for free and open access by the Physical Therapy at UKnowledge. It has been accepted for inclusion in Physical Therapy Faculty Publications by an authorized administrator of UKnowledge. For more information, please contact UKnowledge@lsv.uky.edu. 


\title{
Arm Dominance Does Not Influence Measures of Scapular Muscle Strength and Endurance in Healthy Individuals
}

\author{
Digital Object Identifier (DOI) \\ http://dx.doi.org/10.3233/PPR-150056 \\ Notes/Citation Information \\ Published in Physiotherapy Practice and Research, v. 36, no. 2, p. 87-95. \\ (C) IOS Press and the authors. All rights reserved.
}

The copyright holders have granted the permission for posting the article here.

The document available for download is the authors' post-peer-review final draft of the article. 


\title{
Arm dominance does not influence measures of scapular muscle strength and endurance in healthy individuals
}

\author{
Joseph M. Day ${ }^{\mathrm{a}, *}$, Heather Bush ${ }^{\mathrm{b}}$, Arthur J. Nitz ${ }^{\mathrm{c}}$ and Tim L. Uhl ${ }^{\mathrm{d}}$ \\ ${ }^{a}$ Department of Physical Therapy, University of South Alabama, Mobile, AL, USA \\ ${ }^{\mathrm{b}}$ Department of Biostatistics, University of Kentucky, Lexington, KY, USA \\ ${ }^{\mathrm{c}}$ Division of Physical Therapy, University of Kentucky, Lexington, KY, USA \\ ${ }^{\mathrm{d}}$ Division of Athletic Training, University of Kentucky, Lexington, KY, USA
}

\begin{abstract}
.
BACKGROUND PURPOSE: Scapular muscle performance is potentially influenced by arm dominance. The purpose of this study was to investigate the effect of arm dominance on clinical measures of scapulohumeral muscle strength and endurance. METHODS: Thirty-two healthy individuals between the ages of 30 and 65 years were recruited to participate. Scapular muscle strength of the upper trapezius (UT), middle trapezius (MT), lower trapezius (LT), and serratus anterior (SA) were recorded with a hand held dynamometer. One scapulohumeral isometric muscle endurance task was performed in prone. The order of testing (strength and endurance) was randomized for each individual. Dominant to non-dominant strength and endurance measures were compared with paired $t$-tests.

RESULTS: Arm dominance was significantly higher for UT strength $(p<0.001)$ and endurance $(p=0.015)$. However, the differences between the dominant and non-dominant limbs were not beyond minimal detectable change values.

CONCLUSION: It does not appear that scapulohumeral muscle strength and endurance is clinically different for the dominant and non-dominant limbs in a middle age healthy population.
\end{abstract}

Keywords: Serratus anterior, trapezius, hand held dynamometer

\section{Introduction}

Alterations in scapular kinematics, muscle activity, and muscle strength have been associated with a number of upper extremity dysfunctions [1-4]. In addition, upper extremity functional activities like hand writing, feeding, grooming, reaching overhead, and throwing appear to require scapular muscle activation $[5,6]$. Therefore, a thorough assessment of scapular muscle

${ }^{*}$ Corresponding author: Joseph M. Day, PhD, MSPT, OCS, CIMT, Assistant Professor, University of South Alabama, Pat Capps Covey College of Allied Health Professions, Department of Physical Therapy, HAHN 2011, 5721, Drive N., Mobile, AL 36688-0002, USA. Tel.: +1 251445 9330; Fax: +1 251445 9238; E-mail: josephday@southalabama.edu. parameters is potentially important in treating associated impairments and restoring function of the upper extremity.

There have been many reported techniques for assessing scapular muscle parameters including evaluation of scapular kinematics [7], scapular muscle electromyography (EMG) [8, 9], scapular muscle strength testing with a hand held dynamometer (HHD) [10-12], and sustained isometric upper extremity muscle endurance testing targeting the scapular muscles [11, 13]. Clinically, tools for measuring scapular kinematics and EMG activity are time intensive and expensive, whereas measures of scapular muscle strength and endurance may be more easily performed by clinicians. In addition, studies using a HHD have 
demonstrated good inter rater reliability and the HHD has demonstrated good sensitivity in detecting differences between patients with shoulder pathologies and healthy controls $[10,14]$

In the literature, scapular muscle strength and endurance are typically assessed in the population of interest and then compared to a matched control group $[3,13,15]$. However, clinicians often compare values obtained on a patient's involved limb to the uninvolved limb, thus making the assumption that there is symmetry between sides in healthy individuals. To that end, empirical evidence suggests that arm dominance might be a confounding factor when making an involved to uninvolved upper extremity strength comparison in patients. The dominant upper extremity has been found to be stronger during grip and elbow strength testing in a healthy population $[16,17]$. More closely related to the scapula, multiple studies have found that arm dominance does not affect shoulder strength or strength ratios in several planes of motion [18-20]. Alternatively, two studies found increased shoulder external-internal rotation isokinetic strength ratios in the dominant arm [21, 22]. Although the literature is inconsistent, it cannot be assumed that arm dominance does not influence limb to limb comparisons in patients.

Scapular muscle strength has been shown to be influenced by activity level of the individual. Individuals with increased overhead activity levels demonstrated increased upper trapezius (UT), serratus anterior (SA), and middle trapezius (MT) strength compared to individuals who rated themselves as less active [12]. The only exception to this difference was the lower trapezius (LT) as the strength was equal between both groups [12]. It is reasonable to assume that the dominant limb is more frequently used in daily activities compared to the non-dominant limb; therefore this data suggests there may be increased UT, SA, and MT strength in the dominant limb compared to the non-dominant limb. However, no studies have directly investigated the effects of arm dominance on scapular muscle strength or endurance in healthy individuals [12].

The purpose of this study was to investigate the effect of arm dominance on scapular muscle strength, measured with a HHD, and scapular muscle endurance in healthy individuals. The researchers hypothesize that healthy individuals will demonstrate significantly higher dominant muscle strength for their SA, MT, and UT but no difference for the LT compared to the non-dominant arm. The authors hypothesize that the dominant arm will demonstrate longer static, scapular muscle endurance times compared to the nondominant arm.

\section{Methods}

\subsection{Experimental approach to the problem}

A cross sectional study design was used to investigate the difference in scapular muscle strength between the dominant and non-dominant limbs in healthy individuals. More specifically, a HHD was used to investigate strength of the UT, LT, MT, and SA muscles using previously established methods [10].

In addition to acting as mobilizers, scapular muscles are thought to act as stabilizers [23]. Therefore a static endurance test was also chosen as an assessment for static stabilization. Little has been published on assessing scapular muscle endurance, however, a common method to assess stabilizing musculature in the lumbar spine is a sustained isometric time to fatigue task [24]. For the purpose of this study, a sustained isometric hold in the prone position with the arm abducted to $135^{\circ}$ was chosen because this position is known to activate a variety of scapular muscles $[8,25,26]$. The sustained isometric time to fatigue task was modified from $90^{\circ}$ of abduction, reported by Johnson et al., to $135^{\circ}$ of abduction for this study [13].

\subsection{Participants}

It was determined, a priori, that a sample size of 32 participants would provide over $90 \%$ power to our study to detect a minimal difference of $3.6 \mathrm{~kg}$ $(35.32 \mathrm{~N})$. Therefore, sample of 32 healthy volunteers (mean age $=44.4 \pm 9.78$ years and mean $\mathrm{BMI}=24.86 \pm 4.12 \mathrm{~kg} / \mathrm{m}^{2}$ ) were recruited from the Central KY area. Participants were recruited by email, flyers, and word of mouth. To be included in the study, participants had to be between the ages of 30 and 65 years and demonstrate the ability to tolerate and maintain the instructed test positions. (This age range was chosen because the methodology used for scapular muscle strength assessment was replicated from a previous study that included patients with a mean age of 43 years [10]. Participants were excluded from the study if they reported current or history of (less than 6 months) upper quarter musculoskeletal 
condition, had surgery in the last 6 months on the trunk or upper quarter, or reported a disability score of greater than $10 \%$ as measured by the Quick version of the Disability of the Arm, Shoulder, and Hand (QuickDASH) questionnaire [27].

\subsection{Procedure}

For descriptive purposes, all participants completed a demographic questionnaire which included shoulder activity levels (SAL) [28] and occupational physical demand level as measured by the Dictionary of Occupational Titles [29]. The SAL questionnaire has been shown to be a reliable and valid tool for assessing self-reported activity levels [28].

All dependent variables were collected and analyzed by the primary investigator. A 5 minute rest period was given to the patients after each group of dependent variables were measured to allow time for muscle fatigue recovery [30].

The order for scapular muscle measurements were randomized (HHD testing and endurance testing). The order for strength testing (targeted muscle - UT, MT, LT, and SA) and the first limb tested (dominant versus non-dominant) was also randomized using Microsoft Excel 2007. For the purpose of calculating intra-rater reliability for the endurance task only, 12/32 participants agreed to return one week later so that a second measure of endurance could be collected. In order to minimize the effect muscle training on endurance between visits, all participants returning for a second endurance test were asked to resume their normal activity levels between testing periods.

\section{Hand Held Dynamometer Manual Muscle Test-} ing. A Lafayette (Nicholas) Microfet HHD (Lafayette, IN) USA was used to record force production of the patient. The procedure used to measure scapular muscle strength was adapted from a previous study that reported good between day intra rater reliability for scapular dynamometer strength measurements (ICCs 0.75 to 0.97 ) [10]. Three maximum voluntary contractions (MVCs) for both the dominant and non-dominant sides were recorded. The investigator instructed the patient to push into the dynamometer with their maximum effort, holding for a 5 second duration. Participants were instructed to slowly build up their force production to their maximum force before the end of the 5 seconds. The MVC

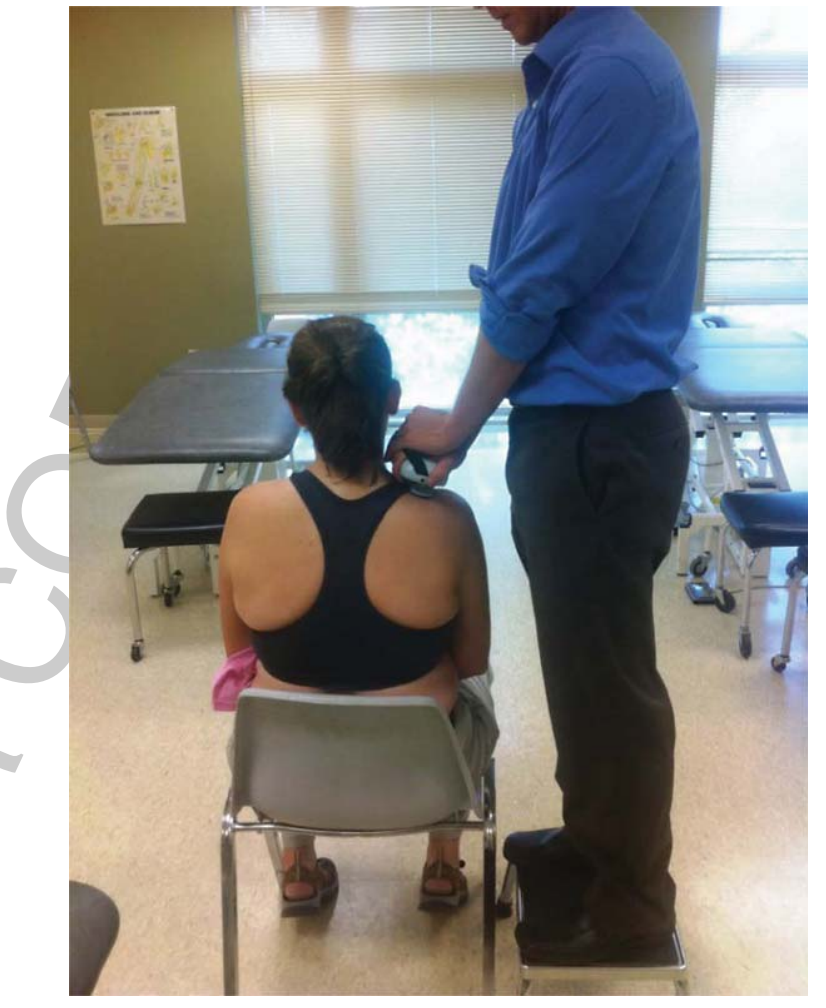

Fig. 1. Upper Trapezius Strength Testing.

was recorded by the assessor. An attempt was made to isolate the following muscles.

- Upper Trapezius - While the patient was in a seated position, the dynamometer was placed on the superior aspect of the scapula, proximal to the acromion. The patient was asked to elevate his/her shoulder against resistance as shown in Fig. 1 [10].

- Serratus Anterior - The patient was positioned supine with the shoulder and elbow flexed to $90^{\circ}$. The dynamometer was placed on the olecranon of the elbow and resistance was given along the humeral axis. The therapist positioned themselves as shown in Fig. 2 [10].

- Middle Trapezius - The patient was positioned prone with the elbow extended and shoulder held to $90^{\circ}$ abduction. The dynamometer was placed on the spine of the scapula, in between the acromion and the medial superior border of the scapula. The subject was instructed to lift his/her arm upward, while resistance with the dynamometer was being applied in the lateral direction. The assessor positioned themselves as shown in Fig. 3 [10]. 


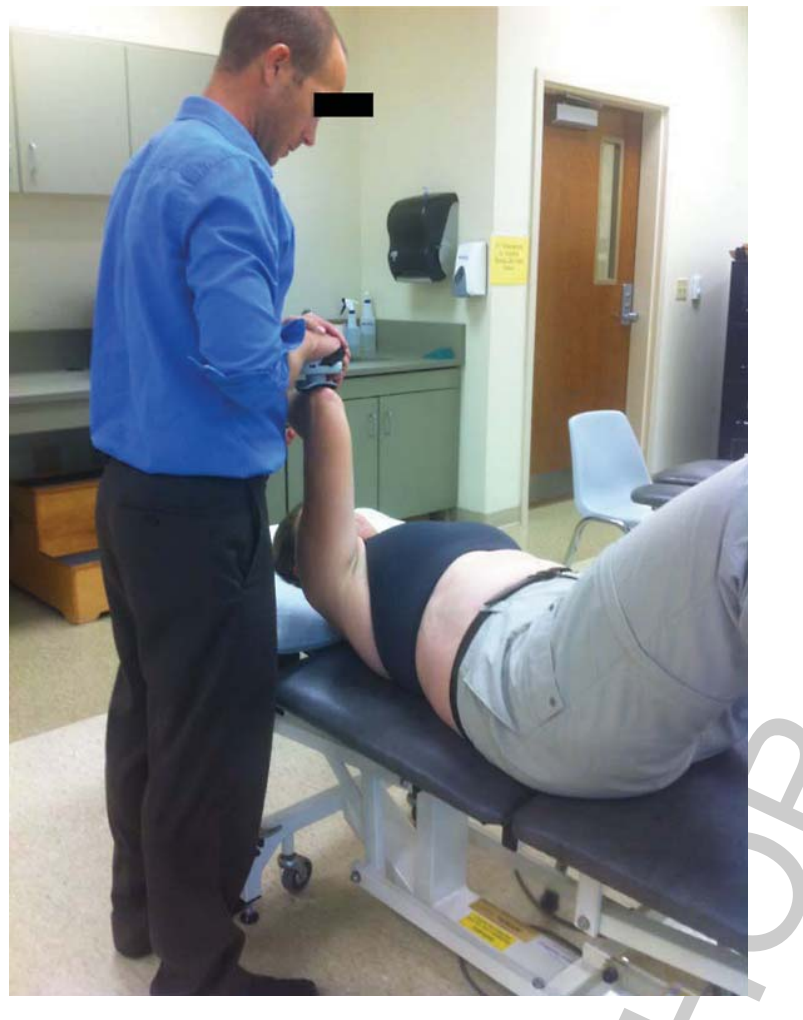

Fig. 2. Serratus Anterior Strength Testing.

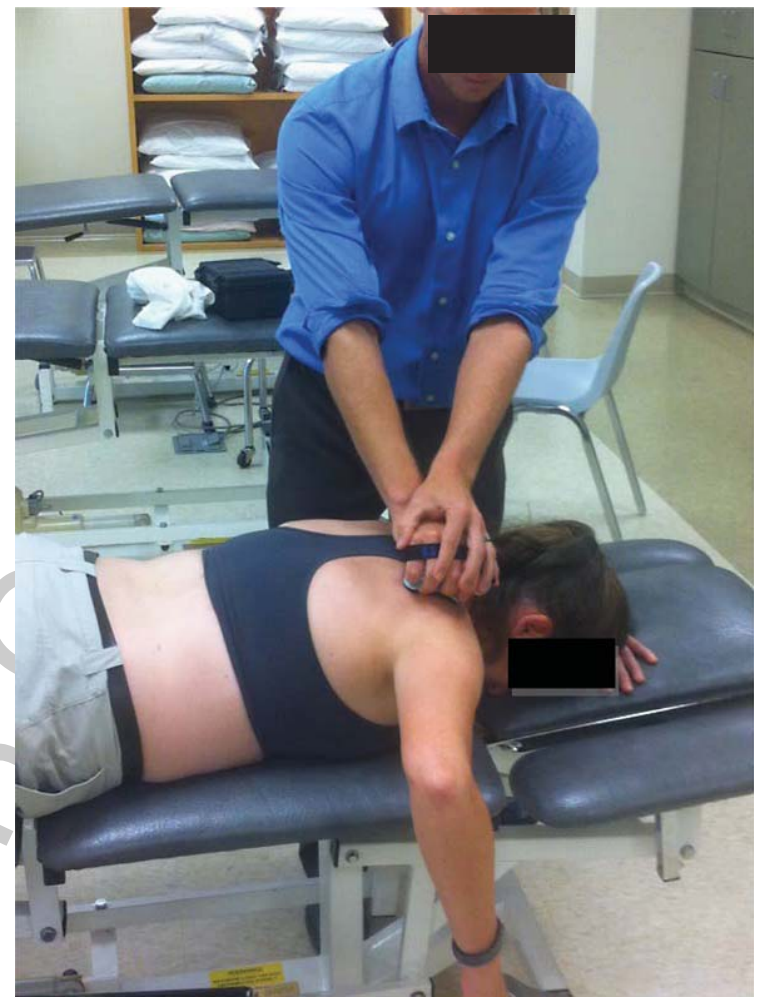

Fig. 3. Middle Trapezius Strength Testing.

shoulder abduction. The subject was then asked to elevate and hold their arm to the established level for as long possible. The test was terminated when the subject voluntarily lowered their upper extremity or if the subject's distal radius was no longer contacting the level $[11,13]$ (Fig. 5).

\subsection{Statistical analyses}

\subsubsection{Reliability}

Analysis was performed using Statistical Program for the Social Sciences (SPSS) version 20. Type A intraclass correlation coefficients (ICCs) along with their $95 \%$ confidence intervals were used to compare the test retest reliability for all strength measures and endurance for both the dominant and non-dominant limb. ICCs $(3,3)$ for strength were calculated within day, whereas endurance ICCs $(3,1)$ were between day. The standard error of the measure (SEM) and minimal detectable change scores (MDC) were also calculated. 


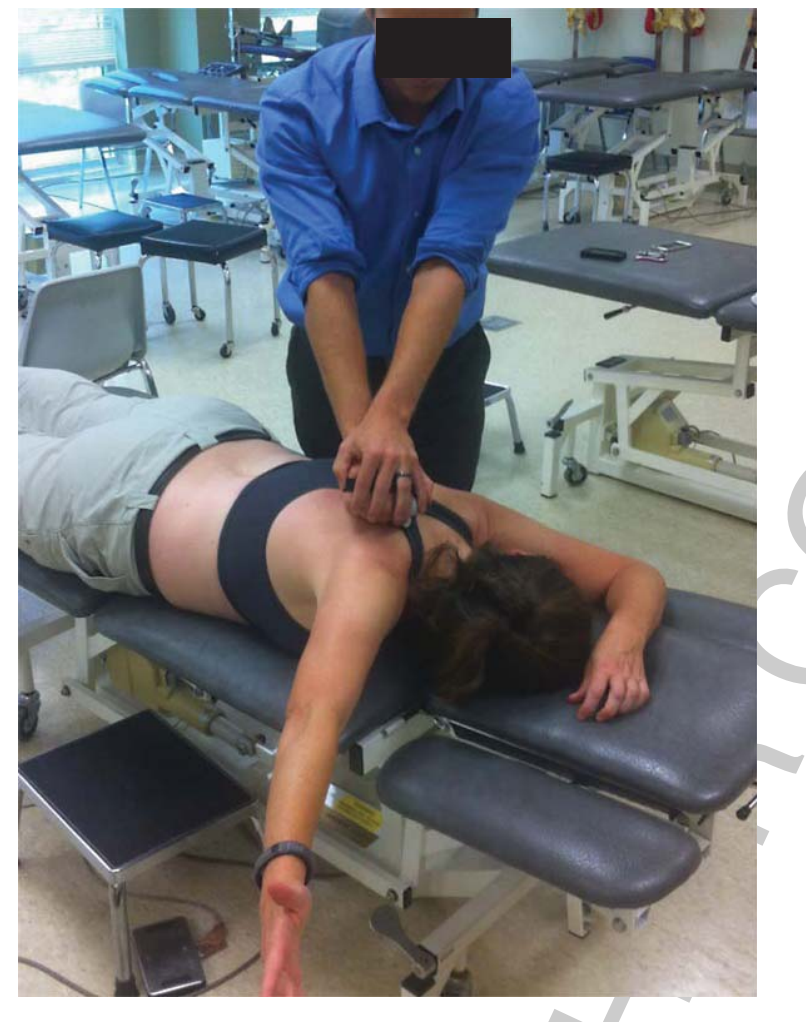

Fig. 4. Lower Trapezius Strength Testing.

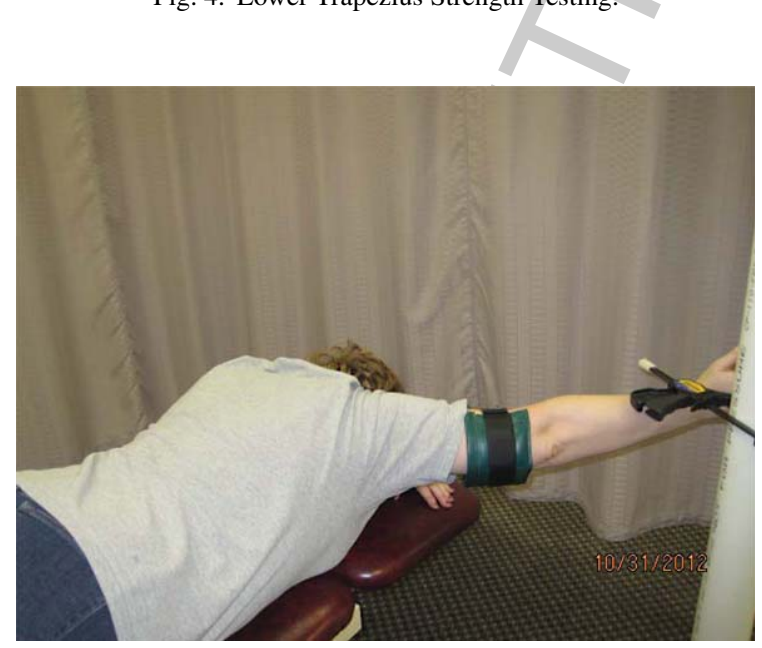

Fig. 5. Scapular Muscle Endurance Test.

\subsubsection{Scapular muscle measures in dominant and non-dominant limbs}

It was determined that a sample size of 32 participants would provide $91 \%$ power to detect a minimal difference of $3.6 \mathrm{~kg}(35.32 \mathrm{~N})$ assuming a common standard deviation of $6.0 \mathrm{~kg}(58.86 \mathrm{~N})$ with an alpha
Table 1

Subject demographics

\begin{tabular}{llcc}
\hline Item & Subgroup & $\mathrm{N}$ & Percentage (\%) \\
\hline Gender & Male & $15 / 32$ & 46.9 \\
\multirow{2}{*}{ Dominant side } & Female & $17 / 32$ & 53.1 \\
& Right & $31 / 32$ & 96.9 \\
Physical demand level & Left & $1 / 32$ & 3.1 \\
& Sedentary & $14 / 32$ & 43.8 \\
& Light & $9 / 32$ & 28.1 \\
& Medium & $8 / 32$ & 25 \\
Shoulder activity level & Heavy & $1 / 32$ & 3.1 \\
& Low & $15 / 32$ & 47 \\
& High & $17 / 32$ & 53 \\
\hline
\end{tabular}

Shoulder Activity Level scores are based on a self-reported questionnaire with a total possible score of 25 . Low scores indicate low activity and high scores indicate high activity. Those who scored 0-12 were placed in the low subgroup and those scoring 13-25 were placed in the high subgroup.

value of 0.05 . The minimal difference and standard deviation values were chosen from a previous study reporting SA HHD force values [10].

Prior to data analysis, Kolmogorov-Smirnov tests for normality and Q-Q Plots confirmed that our data was normally distributed. Therefore, separate paired $t$ tests were used to assess the difference in strength between the dominant and non-dominant limbs for the UT, SA, MT, and LT. The mean values used to compare sides were the average of the 3 trials taken for each muscle. Separate paired $t$ tests were also used to assess the differences in endurance times between the dominant and non-dominant limbs. The level of significance was set $a$ priori at $p<0.05$.

\section{Results}

Descriptive analysis with means and standard deviations are provided in Table 1.

\subsection{Reliability}

Within day ICCs, SEM, and MDC for each of the hand held dynamometer strength tests are presented in Table 2. The intra-session reliabilities (ICC $>0.85$ ) were good for all muscles being tested with the HHD [31]. Between day ICCs, SEM, and MDC for the endurance test are presented in Table 3. The inter-session endurance reliabilities $(I C C=0.91)$ were excellent for both limbs [31]. 
Table 2

Within day reliability for hand held dynamometer scapular muscle tests

\begin{tabular}{|c|c|c|c|c|c|c|}
\hline \multirow[t]{2}{*}{ Muscle } & \multicolumn{3}{|c|}{ Force $(\mathrm{N})$} & \multirow[t]{2}{*}{$\operatorname{ICC}(95 \% \mathrm{CI})$} & \multirow[t]{2}{*}{$\operatorname{SEM}(\mathrm{N})$} & \multirow[t]{2}{*}{$\operatorname{MDC}_{90}(\mathrm{~N})$} \\
\hline & Measure 1 & Measure 2 & Measure 3 & & & \\
\hline \multicolumn{7}{|l|}{ Upper Trapezius } \\
\hline Dominant & $238.77(61.60)$ & $232.30(59.74)$ & $232.69(64.45)$ & $0.96(0.94,0.98)$ & 10.59 & 24.62 \\
\hline Non-dominant & $219.25(54.64)$ & $211.50(52.78)$ & $215.53(52.68)$ & $0.94(0.89,0.97)$ & 12.75 & 29.72 \\
\hline \multicolumn{7}{|l|}{ Middle Trapezius } \\
\hline Dominant & $151.66(28.94)$ & $155.49(30.41)$ & $155.68(30.90)$ & $0.93(0.88,0.96)$ & 7.75 & 18.15 \\
\hline Non-dominant & $148.82(26.88)$ & $146.17(29.82)$ & $149.11(30.71)$ & $0.88(0.80,0.93)$ & 9.71 & 22.56 \\
\hline \multicolumn{7}{|l|}{ Lower Trapezius } \\
\hline Dominant & $125.57(28.55)$ & $127.14(29.23)$ & $123.21(29.23)$ & $0.86(0.76,0.92)$ & 13.93 & 22.96 \\
\hline Non-dominant & $123.21(39.04)$ & $122.13(32.67)$ & $129.10(30.61)$ & $0.85(0.75,0.92)$ & 17.75 & 29.23 \\
\hline \multicolumn{7}{|l|}{ Serratus Anterior } \\
\hline Dominant & $245.05(59.55)$ & $249.08(51.40)$ & $248.68(54.35)$ & $0.91(0.84,0.95)$ & 16.09 & 37.28 \\
\hline Non-dominant & $233.18(48.76)$ & $235.93(49.74)$ & $237.30(48.46)$ & $0.92(0.86,0.96)$ & 13.44 & 31.4 \\
\hline
\end{tabular}

Abbreviations: $N=$ Newtons, ICC $=$ intraclass correlation coefficient, $\mathrm{SEM}=$ standard error of the measure, $\mathrm{MDC} 90=90 \%$ boundary limit for the minimal detectable change. $N=32$.

Table 3

Between day reliability for the scapular muscle endurance test

\begin{tabular}{lrrrrr}
\hline Endurance Testing & \multicolumn{2}{c}{ Time (s) } & ICC (95\% CI) & SEM(s) & \multicolumn{2}{c}{ MDC90(s) } \\
\cline { 2 - 5 } & Measure 1 & Measure 2 & & \\
\hline Dominant & $89.00(38.81)$ & $103.17(44.00)$ & $0.91(0.71,0.97)$ & 10.31 & 24 \\
Non-dominant & $78.17(35.95)$ & $89.42(41.27)$ & $0.91(0.73,0.97)$ & 10.91 & 25.38 \\
\hline
\end{tabular}

Abbreviations: $s=$ seconds, ICC $=$ intraclass correlation coefficient, $\mathrm{SEM}=$ standard error of the measure, MDC $90=90 \%$ boundary limit for the minimal detectable change. $N=12$.

\subsection{Dominant to non-dominant comparisons}

There was a statistically significant increase in average peak force values on the dominant side for the UT $(p \leq 0.001)$ when compared to the non-dominant limb. However, the differences in average peak force values between the dominant and non-dominant limbs were not beyond the $\mathrm{MDC}_{90}$ reported in Table 2 . There were no statistically significant differences in SA $(p=0.052)$, LT $(p=0.759)$ or MT $(p=0.08)$ peak force values when comparing the dominant to non-dominant limbs (Fig. 6).

For the endurance measures, there was a statistically significant increase in timed endurance $(p=0.015)$ for the dominant limb $($ mean $=87.41 \pm 34.38 \mathrm{~s})$ compared to the non-dominant limb (mean $=78.53 \pm 36.38 \mathrm{~s}$ ). Similar to peak force value results, the average difference between limbs was not beyond measurement error.

\section{Discussion}

Our hypotheses were partially confirmed as we found significantly higher dominant limb UT strength

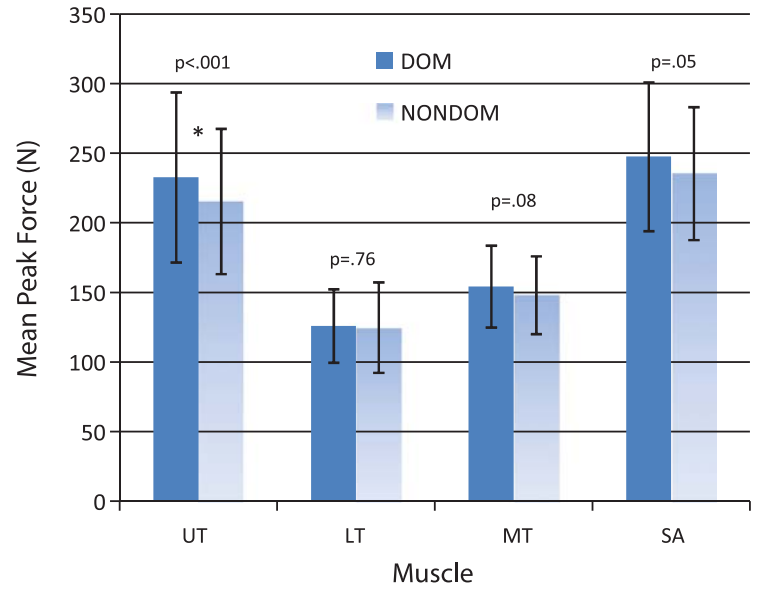

Fig. 6. Dominant versus Non-dominant Scapular Muscle Strength. Mean force values and standard deviations for scapular muscles are similar when comparing the dominant to nondominant limbs in middle age healthy individuals. Abbreviations: $\mathrm{DOM}=$ Dominant, NONDOM = non-dominant, UT = upper trapezius, $\mathrm{LT}=$ lower trapezius, $\mathrm{MT}=$ middle trapezius, $\mathrm{SA}=$ serratus anterior. *indicates significant different at $p<0.05$.

and scapulohumeral muscle endurance but no significant difference in SA, LT or MT strength. Although there was a statistically significant increase in UT 
strength and scapulohumeral muscle endurance for the dominant limb compared to the non-dominant limb, the differences were small and do not exceed the measurement error of our technique. Therefore, the results do not appear to be clinically meaningful.

\subsection{Strength with a HHD}

Our results add to the limited body of knowledge for the influence of arm dominance on scapular muscle strength. Cools and others investigated the effect of dominance on isometric scapular muscle strength in elite tennis players [32]. Unlike our study, resistance was applied to the distal upper extremity for testing the SA, LT, and MT. Cools and others also found a significant increase in UT and SA strength for the dominant compared to the non-dominant limb but no differences for the LT and MT [32]. Unlike our study, Cools and others found a significant increase in strength in the dominant SA [32]. The patient population and the technique for applying resistance could account for the different results when comparing our study to Cools [32]. For example, in our study, only half the population chosen were considered to have a high shoulder activity level, whereas elite tennis players in the Cools study would all seemingly report high shoulder activity levels. In direct contrast to our findings, another study found higher protraction isokinetic strength on the nondominant side in elite gymnasts [33]. However, caution should be exercised when comparing our results to the aforementioned study because it is difficult to compare isometric to isokinetic results.

The statistically significant increased strength values for the dominant UT did not exceed the MDC value. As a result, the mean difference between dominant and non-dominant UT strength do not appear to be clinically meaningful because the differences did not exceed the calculated measurement error. For example, the dominant UT was nearly $18 \mathrm{~N}$ stronger on average than the non-dominant limb and was considered to be statistically significant. However, the MDC values calculated for the UT indicates that an approximate $30 \mathrm{~N}$ change was needed to exceed measurement error of the technique. Overall, arm dominance does not need to be considered when screening scapular muscle strength in healthy individuals of the same population.

Caution should be exercised in making a broad interpretation of our results. It is possible that the influence of dominance on scapular muscle strength could be more pronounced in healthy individuals that routinely perform higher levels of shoulder activity. For example, in a general population of healthy individuals, it has been demonstrated that there are no differences in shoulder rotation strength when comparing the dominant to non-dominant limb [18-20, 34]. On the contrary, a number of studies looking at specific athletic populations have found increased shoulder and scapular muscle strength for the dominant compared to the non-dominant arms [17, 21, 22, 32, 34]. According to these studies, the differences in strength between the dominant and non-dominant limb, for several tested motions, exceeded a $10 \%$ difference. In reviewing our data, it appears that a difference of approximately $10 \%$ would be needed to meet MDC values for the muscles tested. Therefore, populations of individuals that consistently perform high level upper extremity tasks, such as overhead athletes, may develop motor adaptations that result in meaningful increased strength of the dominant limb.

Future studies are needed to investigate dominant and non-dominant scapular muscle strength in a larger population of individuals stratified into groups of shoulder activity levels using the previously described SAL. This will provide a more complete normative database to allow clinicians to make accurate and meaningful interpretations of patient's scapular muscle strength.

\subsection{Scapulohumeral muscle endurance}

The ability to clinically measure scapulohumeral endurance has been reported in the literature yet the reliability and measurement error has yet to be investigated [11, 13]. Because we found the described endurance test to be reliable between days, this test has the potential to be used as a clinical assessment tool. In addition, this was the first study to report a minimal detectable change (MDC) for a sustained scapulohumeral isometric endurance test. To that end, a change of 25 seconds was determined to be the MDC needed to reflect a true change of an individual's endurance time. Similar to our findings with UT strength, there was a significant increase in scapulohumeral muscle endurance for the dominant limb but the differences were well below measurement error. Therefore, it does not appear that dominance plays a meaningful factor in scapulohumeral muscle endurance for this population. 
Clinical interpretation of our endurance results should be performed cautiously. Upon closer look at the reliability results for endurance, it appears that a learning effect may be occurring between the first and second testing session. For example the mean endurance time increased from day 1 to day 2, approximately 10 seconds, independent of the limb being tested. As suggested from a similar studies testing isometric trunk endurance, multiple trials may be needed before a true baseline measure is obtained [35]. In addition, the endurance MDC may be inflated and would most likely diminish in our study if the ICCs were taken on the second and third trial of testing.

In addition to considering a learning effect, muscular compensation during the endurance test should also be considered when interpreting the results. Although the position is known to produce high levels of EMG activity in the LT, a strong influence of the UT and other posterior shoulder muscles cannot be ruled out $[8,25,26]$. In the current study, monitoring of the UT was performed by the evaluator, but compensations were difficult to detect. Therefore, it is possible that the endurance results were influenced by the UT.

Future studies are needed to investigate the limitations of the described scapulohumeral muscle endurance test. Most importantly, the validity of the test should be investigated by concurrently measuring EMG activity of the posterior shoulder and scapulothoracic muscles. It would also be interesting to quantify compensations through EMG analysis during the endurance test.

\subsection{Limitations}

There are two important limitations to this study that should be recognized when interpreting the data. The limb being tested was not blinded by the investigator and thus could result in potential investigator bias of the results. Because the researcher's general hypothesis was that the dominant limb would be statistically stronger and demonstrate longer endurance compared to the non-dominant limb, it is possible that the mean dominant limb values were slightly inflated or that the mean non-dominant limbs values were slightly lower. Nevertheless, as stated earlier, the difference in outcome measures between limbs were not clinically significant. In addition, the validity for isolating SA and MT strength has not been established. Therefore, recruitment of other musculature was likely during testing. For example, the data reported for SA strength could be influenced not only by the serratus anterior but also by the pectoralis major.

\section{Practical application}

Overall, it does not appear that clinical measures of scapulohumeral muscle strength and endurance is clinically different for the dominant and non-dominant limbs in a general middle age healthy population. Therefore, using these methods, comparing strength measures bilaterally for the MT, SA, and LT is valid among healthy individuals in this population. In addition, the normal data reported could be used by clinicians to compare scapular strength and endurance values to patients with similar characteristics. Future studies are needed to determine the effect of arm dominance on scapular muscle performance with individuals stratified by shoulder activity levels. Research is also needed to validate the described testing procedures.

\section{References}

[1] Fayad F, Roby-Brami A, Gautheron V, Lefevre-Colau MM, Hanneton S, Fermanian J, et al. Relationship of glenohumeral elevation and 3-dimensional scapular kinematics with disability in patients with shoulder disorders. Journal of Rehabilitation Medicine 2008;40:456-60.

[2] Ludewig PM, Reynolds JF. The association of scapular kinematics and glenohumeral joint pathologies. J Orthop Sports Phys Ther 2009;39:90-104.

[3] Lucado AM, Kolber MJ, Cheng MS, Echternach JL, Sr. Upper extremity strength characteristics in female recreational tennis players with and without lateral epicondylalgia. J Orthop Sports Phys Ther 2012;42:1025-31.

[4] Rundquist PJ, Dumit M, Hartley J, Schultz K, Finley MA. Three-dimensional shoulder complex kinematics in individuals with upper extremity impairment from chronic stroke. Disabil Rehabil 2012;34:402-7.

[5] Naider-Steinhart S, Katz-Leurer M. Analysis of proximal and distal muscle activity during handwriting tasks. Am J Occup Ther 2007;61:392-8.

[6] Rundquist PJ, Obrecht C, Woodruff L. Three-dimensional shoulder kinematics to complete activities of daily living. Am J Phys Med Rehabil 2009;88:623-9.

[7] Lukasiewicz AC, McClure P, Michener L, Pratt N, Sennett B. Comparison of 3-dimensional scapular position and orientation between subjects with and without shoulder impingement. J Orthop Sports Phys Ther 1999;29:574-83; discussion 84-6.

[8] Moseley JB, Jr., Jobe FW, Pink M, Perry J, Tibone J. EMG analysis of the scapular muscles during a shoulder rehabilitation program. The American Journal of Sports Medicine 1992;20:128-34. 
[9] Phadke V, Camargo P, Ludewig P. Scapular and rotator cuff muscle activity during arm elevation: A review of normal function and alterations with shoulder impingement. Rev Bras Fisioter 2009;13:1-9.

[10] Michener LA, Boardman ND, Pidcoe PE, Frith AM. Scapular muscle tests in subjects with shoulder pain and functional loss: Reliability and construct validity. Phys Ther 2005;85:1128-38.

[11] Tate A, Turner GN, Knab SE, Jorgensen C, Strittmatter A, Michener LA. Risk factors associated with shoulder pain and disability across the lifespan of competitive swimmers. J Athl Train 2012;47:149-58.

[12] Turner N, Ferguson K, Mobley BW, Riemann B, Davies G. Establishing normative data on scapulothoracic musculature using handheld dynamometry. J Sport Rehabil 2009;18: 502-20.

[13] Johnson EG, Godges JJ, Lohman EB, Stephens JA, Zimmerman GJ, Anderson SP. Disability self-assessment and upper quarter muscle balance between female dental hygienists and non-dental hygienists. J Dent Hyg 2003;77:217-23.

[14] Celik D, Sirmen B, Demirhan M. The relationship of muscle strength and pain in subacromial impingement syndrome. Acta Orthopaedica et Traumatologica Turcica 2011;45:79-84.

[15] O'Sullivan C, McCarthy Persson U, Blake C, Stokes M. Rehabilitative ultrasound measurement of trapezius muscle contractile states in people with mild shoulder pain. Manual Therapy 2012;17:139-44.

[16] Clerke A, Clerke J. A literature review of the effect of handedness on isometric grip strength differences of the left and right hands. Am J Occup Ther 2001;55:206-11.

[17] Demura S, Miyaguchi K, Aoki H. The difference in output properties between dominant and nondominant limbs as measured by various muscle function tests. J Strength Cond Res 2010;24:2816-20.

[18] Cortez PJ, Tomazini JE, Valenti VE, Correa JR, Valenti EE, Abreu LC. A new device to measure isometric strength in upper limbs: Comparison between dominant and nondominant limbs. Clinics (Sao Paulo). 2011;66:351-4.

[19] Wang HK, Macfarlane A, Cochrane T. Isokinetic performance and shoulder mobility in elite volleyball athletes from the United Kingdom. Br J Sports Med 2000;34:39-43.

[20] Hughes RE, Johnson ME, O'Driscoll SW, An KN. Normative values of agonist-antagonist shoulder strength ratios of adults aged 20 to 78 years. Arch Phys Med Rehabil 1999;80:1324-6.

[21] Mulligan IJ, Biddington WB, Barnhart BD, Ellenbecker TS. Isokinetic profile of shoulder internal and external rotators of high school aged baseball pitchers. J Strength Cond Res 2004;18:861-6.
[22] Alfredson H, Pietila T, Lorentzon R. Concentric and eccentric shoulder and elbow muscle strength in female volleyball players and non-active females. Scandinavian Journal of Medicine \& Science in Sport 1998;8:265-70.

[23] Mottram SL. Dynamic stability of the scapula. Manual Therapy 1997;2(3):123-31

[24] Inani SB, Selkar SP. Effect of core stabilization exercises versus conventional exercises on pain and functional status in patients with non-specific low back pain: A randomized clinical trial. J Back Musculoskelet Rehabil 2013;26:37-43.

[25] Cools AM, Dewitte V, Lanszweert F, Notebaert D, Roets A, Soetens B, et al. Rehabilitation of scapular muscle balance: Which exercises to prescribe? The American Journal of Sports Medicine 2007;35:1744-51.

[26] Ekstrom RA, Donatelli RA, Soderberg GL. Surface electromyographic analysis of exercises for the trapezius and serratus anterior muscles. The Journal of Orthopaedic and Sports Physical Therapy 2003;33:247-58.

[27] Hunsaker F, Cioffi D, Amadio P, Wright J, Caughlin B. The American academy of orthopaedic surgeons outcomes instruments: Normative values from the general population. Journal of Bone Joint Surgery 2002;84A:208-15.

[28] Brophy RH, Beauvais RL, Jones EC, Cordasco FA, Marx RG. Measurement of shoulder activity level. Clin Orthop Relat Res 2005;439:101-8.

[29] Dictionary of Occupational Titles [updated 2001]. Available from: http://www.occupationalinfo.org/index.html

[30] Stull GA, Clarke DH. Patterns of recovery following isometric and isotonic strength decrement. Med Sci Sports 1971;3: 135-9.

[31] Portney L, Watkins MP. Foundations of Clinical Research: Applications to Practice. 3rd ed. Upper Saddle River, New Jersey: Pearson Prentice Hall; 2009.

[32] Cools AM, Johansson FR, Cambier DC, Velde AV, Palmans T, Witvrouw EE. Descriptive profile of scapulothoracic position, strength and flexibility variables in adolescent elite tennis players. Br J Sports Med 2010;44:678-84.

[33] Cools AM, Geerooms E, Van den Berghe DF, Cambier DC, Witvrouw EE. Isokinetic scapular muscle performance in young elite gymnasts. J Athl Train 2007;42:458-63.

[34] Murray MP, Gore DR, Gardner GM, Mollinger LA. Shoulder motion and muscle strength of normal men and women in two age groups. Clin Orthop Relat Res 1985;192:268-73.

[35] Brotons-Gil E, Garcia-Vaquero MP, Peco-Gonzalez N, VeraGarcia FJ. Flexion-Rotation Trunk Test to Assess Abdominal Muscle Endurance: Reliability, Learning Effect and Sex Differences. J Strength Cond Res 2012;27(6):1602-8 . 